\title{
A Satellite Meteorological Study of Evaporation and Cloud Formation over the Western Pacific under the Influence of the Winter Monsoon*
}

\author{
By Kiyoshi Tsuchiya \\ Japan Meteorological Agency \\ and Tetsuya Fujita \\ The University of Chicago \\ (Manuscript received 11 December 1966, in revised form 20 March 1967)
}

\begin{abstract}
A study of the source regions of winter monsoon clouds in relation to orographic features revealed that the cloud-free paths and the off-shore distance of the initial clouds measured along stream-lines are closely related to the height of the mountains and the intensity of the monsoon. The patterns of clouds after their formation are found to vary according to the vertical wind shear, changing from convection cells with weak shear to transverse bands with moderate shear and longitudinal bands with strong shear. Following the study of cloud formations, the uses of satellite and aerological data in estimating evaporation from the sea surface were explored. It was found that the water content of monsoon clouds is considerably smaller than what might be expected through adiabatic rising processes. The ratio of actual to adiabatic water content was estimated to be about 0.6 over the Sea of Japan and about 0.7 over the western Pacific under the influence of a strong winter monsoon.
\end{abstract}

\section{Introduction}

The Hokuriku District located between the Japan Sea coast and the central mountain range in Honshu is known as one of the heaviest snow areas in the densely populated regions of the world. It is not rare to receive over $1.5 \mathrm{~m}(5 \mathrm{ft})$ of snow in one day paralyzing the entire local and long-distance traffic for several days.

In order to clarify the meteorological reasons for such heavy snowfall, a number of researchers have attempted to find the source regions of the snow clouds over the Sea of Japan. Pioneering study of monsoon clouds by Ishihara et. al. (1947), based upon their observations on board merchant ships between

* The research reported in this paper has been sponsored under the U.S. Japan Cooperative Science Program by the Japan Society for the Promotion of Science under grant GEO-4 and by the U.S. National Science Foundation under grant NSF GF-179 also by the Meteorological Satellite Laboratory, ESSA under grant Cwb WBG-34.
Hokuriku and North Korea, revealed that initial cloud formation takes place only $150 \mathrm{~km}$ off the Korean coast when the monsoon is strong. In their recent studies of the formation and structure of winter monsoon clouds over the Sea of Japan, Asai (1964 and 1966) and Matsumoto and Ninomiya (1965 and 1966) applied aerial photogrammetric methods, uncovering mesoscale configuration of clouds which otherwise could not have been discovered.

The recent development of meteorological satellites now permits us to determine both the height and cover of clouds by using methods developed by Fujita and Grandoso (1965). The present authors have therefore tried to analyze both radiation and photographic data for use in further studies of winter monsoon clouds over both the Sea of Japan and the Pacific Ocean. These satellite data, when combined with studies of radar echoes by Fukatsu (1963) and Tatehira and Fukatsu (1965), are found to be of great value in the study of the processes by which small, 
convective clouds far off the Hokuriku coast develop into snowstorms observed on radarscopes,

Manifestations of winter monsoon clouds over the western Pacific clearly show that their variations are influenced significantly by the vertical wind shear as well as by thermodynamical stability inside the modified monsoon air due to the supply of heat and moisture from the surface. Careful examination of these clouds will verify the relationship between wind shear and the banded structure, as obtained experimentally by Chandra (1938). It also adds more evidence of a large ratio between the diameter of cellular clouds and their height, studied by Krueger and Fritz (1961).

So far, the rate of evaporation from the Japan Sea surface has been estimated by using Jacobs (1942 and 1943) equation, which includes an empirical constant. Based upon an analysis of aerological data from Kagoshima (827) and the Weather Ship, Tango (30N, 135E), Ito (1960) obtained this constant over the Pacific south of Shikoku as 0.14, with relatively small standard deviation. Using the data over the Sea of Japan, however, Ito (1958) had suggested 0.33 as being a realistic value for this constant. Those who studied the heat and moisture balance involving the Sea of Japan and the islands con cluded that the constant proposed by Jacobs results in balanced conditions as far as the winter monsoon is concerned. Studies by Manabe (1957 and 1958), Fujita and Honda (1965), and Ninomiya (1964) include computations of evaporation using the above-mentioned Jacobs' equation.

In order not to reduce the evaporation rate to zero when it is calm, Penman (1956) suggested a formula,

$$
E=0.35\left(e_{s}-e_{0}\right)\left(1+V_{2}\right)
$$

where $E$ gives the evaporation rate in $\mathrm{mm}$. day $^{-1}$ when $e_{s}$ in mb denotes saturation vapor pressure at sea-surface temperature; $e_{0}$, the vapor pressure of the air; and $V_{2}$, the wind speed in mile $\cdot$ day $^{-1}$ at the 2 -m level above the sea surface. This equation gives a small evaporation rate even when it is absolutely calm.
In view of uncertainties inevitable for the computation of evaporation from the sea surface, various avenues leading to more reasonable determination of evaporation by using satellite and aerological data have been explored by the authors. It became evident that the contribution of clouds in the storage of liquid- or solid-state water is important, thus necessitating satellite-borne measurements of cloud cover for the estimation of the water budget.

\section{Source Regions of Winter Monsoon Clouds}

In order to verify the common belief that convective clouds which produce heavy snow along the Japan Sea side of Honshu originate near the center of the Sea of Japan, Ishihara made several trips on board merchant ships between Niigata and Nashin, North Korea during World War II. Based upon their observations, Ishihara et. al., (1947) concluded that there are two regions of frequent cumulonimbi, one near $40 \mathrm{~N}$ and $135 \mathrm{E}$ and the other off the northwest coast of Sado Island. An examination of reports of sea-surface temperatures over the past three years revealed that the Tsushima Current, which flows northeastward off the Honshu coast, branches out north-northeast toward the central Sea of Japan where frequent cumulonimbi were observed by Ishihara. From this evidence, it may be concluded that heavy cumulus to cumulonimbus activity is closely related to regions of warm oceanic current. Ishihara also studied the initial cloud formation off the coast of North Korea along the route of the ships, finding that a cloud-free region extended about $150 \mathrm{~km}$ off-shore when the monsoon was strong and over $300 \mathrm{~km}$ when weak. According to his observations, a few isolated cumuli increase their diameters, gradually changing into stratocumulus as the off-shore distance increases. The cloud bases then lower until well-developed cumulonimbus with light precipitation dominates the area.

From a thermodynamical point of view, an extremely dry, polar air mass from the Asiatic continent must receive a certain amount of heat and moisture from the underlying Japan Sea surface in order to form convective clouds. The cloud-free path, defined as the 
distance between the coast and the first convective cloud measured along the path of low-level winds, will vary according to the rates of evaporation and heating as well as the relative humidity of the initial air mass. It should be noted that the moisture content, especially at low levels, of an air mass that has moved over a mountain range decreases appreciably with the increasing height of the range. As a result, the cloud-free paths should be investigated in relation to the orography that blocks the outflow of an air mass toward the open sea.

Cloud-free paths unaffected by orography in the vicinity are seen over the Great Lakes region in the United States under the influence of the winter monsoon (Fig. 1). The figure

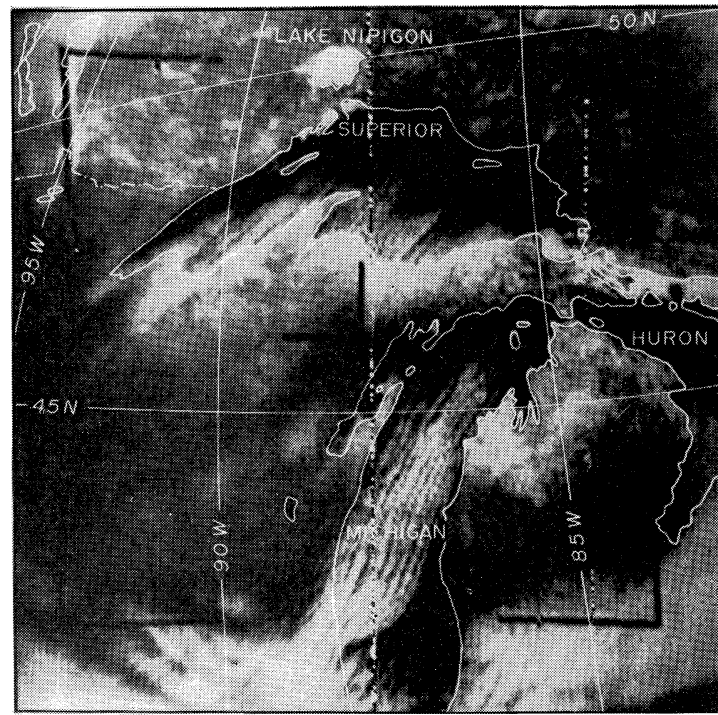

Fig. 1. A TIROS VII photograph showing longitudinal cloud bands forming over the Great Lakes during an outbreak of cold, polar continental air at $1600 \mathrm{CST}$, April 3, 1964. A marked inversion top at $4000 \mathrm{ft}$ above the surface was in existence over the entire region of the photograph.

reveals a large number of cloud streets, some $7 \mathrm{~km}$ apart, originating over Lake Superior and Lake Michigan on April 3, 1964. The vertical wind shear between the cloud-top and lake levels was relatively high, indicating an average of $7 \times 10^{-3} \mathrm{sec}^{-1}$. The measured cloudfree paths over Lake Superior were as long as $80 \mathrm{~km}$, while those over Lake Michigan were no more than $40 \mathrm{~km}$. Such a decrease in the cloud-free path suggests that the cold air mass from Canada received more moisture than that precipitated over upper Michigan before reaching the north shore of Lake Michigan and/or that evaporation from Lake Michigan was quite significant. The cloudfree paths over these lakes seem to be less than half of Ishihara's figure obtained over the Sea of Japan. Nevertheless, the fact that frequent lake snow is observed along the east and south coasts of Lake Michigan indicates that the cloud-free paths are much shorter than the average which of the lake about $100 \mathrm{~km}$.

Extremely short cloud-free paths were photographed over Lake Superior at 5 PM CST, Dec. 17, 1965 by one of the authors on board a Northwest Airlines jet aircraft. As shown in Fig. 2, the mean cloud-free path
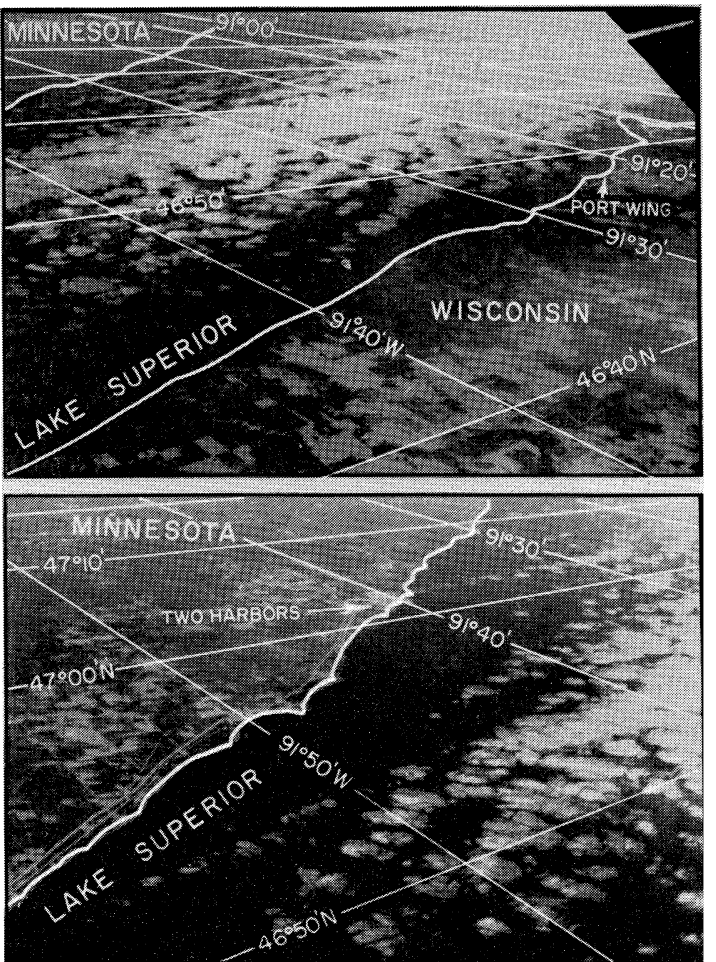

Fig. 2. Aerial photographs of convective clouds forming over the western part of Lake Superior. Taken at about 1700 CST, Dec. 16, 1965 from a Northwest Orient jet between Anchorage and Chicago. Note that one of the lines of clouds in the lower picture originates over the city of Two Harbors, Minnesota. 
was no more than $10 \mathrm{~km}$, thus giving the impression that the lake, except near the shore line, was packed with convective cumuli, their density and size increasing downstream. Of interest, in particular, is a row of cumuli extending from Two Harbors, a small town located on the northwest shore of the lake. The aerial photograph gives the impression that the row originated over the town or right on the shore line. In either case the town would have acted as a source of heat and moisture so as to bring the low-level atmosphere to or near condensation upon slight lifting and additional supply of moisture from the lake surface.

The cloud-free path off the Japan Sea coast of the Asiatic Continent is rather complicated, due to the coastal ranges, Khrebet Sikhote

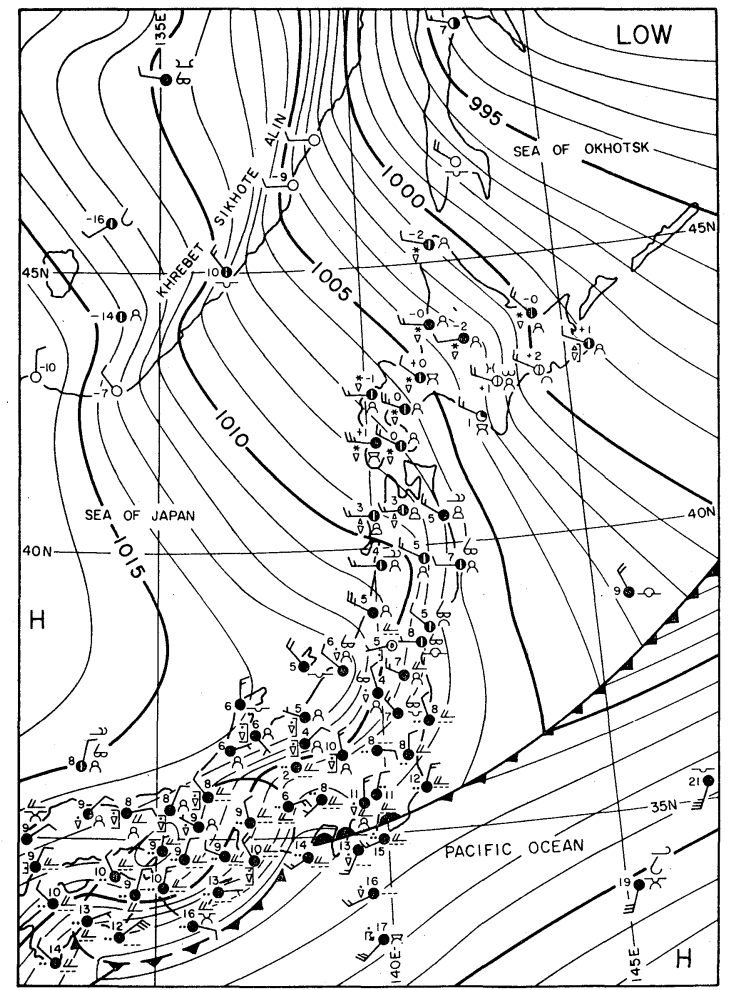

Alin and high mountains in North and South Korea, which give rise to a significant blocking of low-level cold air accumulated over the continent. Major and minor valleys and canyons, however, provide meandering passages for low-level cold air to the Sea of Japan. Some of these passages are not wide enough to transport the cold air mass without modification, Nonetheless, the high-level air reaching the Japan Sea coast after moving over high spots in the ranges is much drier than that reaching the sea through the passages. It is thus expected that the cloud-free paths extending from the openings of the passages are shorter than those from high spots in the ranges.

For the purpose of investigating the cloudfree paths to the lee of Khrebet Sikhote Alin,

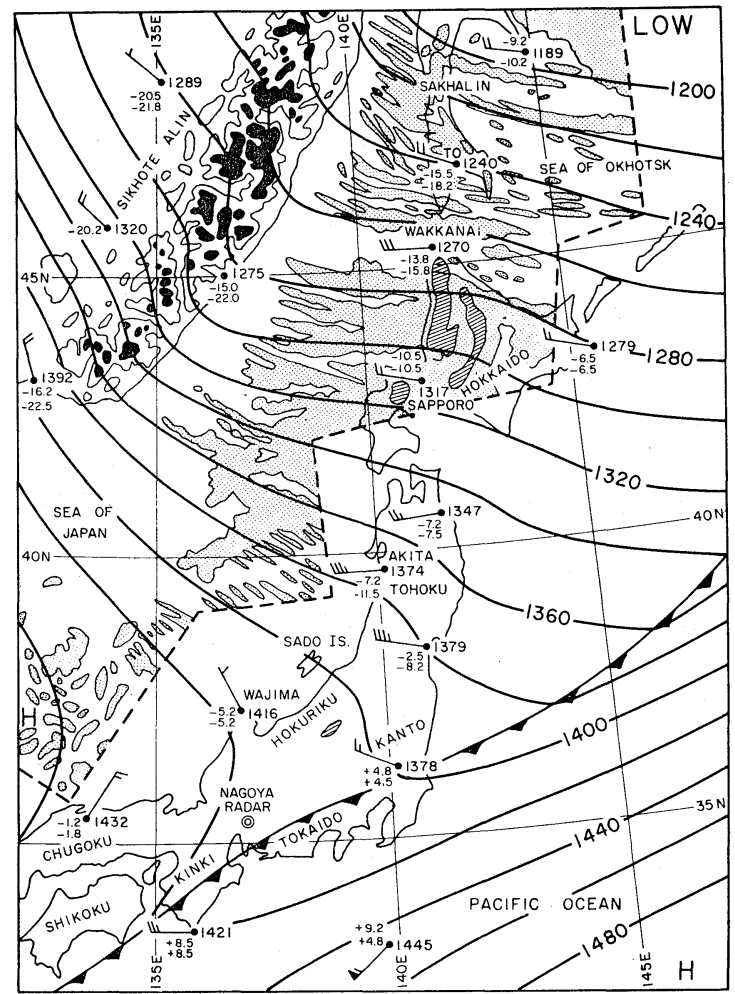

Fig. 3. Left: A surface weather map for 0000Z, Jan. 14, 1964. showing a moderate winter monsoon over northern Japan and a small mesoscale precipitation high over west central Japan. Surface isobars are drawn at intervals of $1 \mathrm{mb}$. Right: Cloud patterns (stippled) over the northern Sea of Japan under the winter monsoon. The 850-mb contours are drawn for every $20 \mathrm{~m}$. Cloud patterns were transferred from three gridded TIROS VII pictures, Frames 6, 8, and 10, taken at 0224, 0225, and 0226Z, Jan. 14, 1964, respectively. Mountains above $1000 \mathrm{~m}$ in the Sikhote Alin are painted. Lower mountains are indicated by $500-\mathrm{m}$ height contours. Hatched areas in Hokkaido and Honshu designate regions of daily precipitation exceeding $10 \mathrm{~mm}$. 
a monsoon situation at 00Z, Jan. 14, 1964 was analyzed in Fig. 3. The left figure, showing a surface map, reveals that northern Honshu, Hokkaido, and Sakhalin are under the influence of a typical monsoon of medium intensity. A cold front extending southwest from an occluded low over the Sea of Okhotsk changes into a stationary-to-warm front along the Pacific coast of Honshu. A mesoscale high, including regions of moderate rain, is seen on the warm front, centered over Kinki. Isobars drawn at $1-\mathrm{mb}$ intervals clearly represent the influence of the mountains upon the northwesterly flow. Note that the drops in sea-level pressure behind these mountains exceed $3 \mathrm{mb}$ locally, The cloud patterns in the right figure were obtained from three gridded frames, Nos. 6, 8, and 10, from Orbit 3085, TIROS VII. These frames were exposed at one-minute intervals centered at 0225Z, which was $2 \mathrm{hr} 25 \mathrm{~min}$ after the map time of the left figure. Through careful comparison between the orographic features of Sikhote Alin and the cloud-free paths extending downstream, it will be found that the higher and more extensive the mountains, the longer the cloud-free paths, and that the average cloud-free path increases southward as the monsoon weakens. The shortest cloudfree path, about $20 \mathrm{~km}$ in the northernmost region, increases to about $100 \mathrm{~km}$ near the latitude of Hokkaido. Along the streamline from the southern top of Sikhote Alin, cloudfree paths exceed $400 \mathrm{~km}$, indicating a good agreement with Ishihara's observation that the paths increase to about $300 \mathrm{~km}$ when the winter monsoon is weak. These findings are also well supported by ESSA and NIMBUS APT pictures received in Japan daily now.

We may, therefore, assume that cloud-free paths are extremely short-in the order of 10 to $50 \mathrm{~km}$-when the monsoon is very strong. With weakening monsoon winds, the paths increase to over $400 \mathrm{~km}$, without permitting convective clouds to from off the west coast of Sakhalin or Hokkaido.

\section{Effects of Orography upon Monsoon Clouds}

Following the estimation of cloud-free paths, we shall elaborate on what will happen to the moisture supplied to a cold air mass from the underlying sea surface. According to Ito (1958), a column of cold air traveling from Vladivostok to Hokuriku will acquire on an average of $18 \mathrm{~mm}$ of water vapor during its passage over the Sea of Japan. While Manabe (1958), Fujita and Honda (1965) obtained 7.5 $\mathrm{mm}$ and $10.5 \mathrm{~mm}$ respectively as an average value of daily evaporation over the Sea of Japan during a strong cold air outbreak from Asiatic continent. On the other hand Matsumoto and Ninomiya (1966) based upon the analyses of energy budget and aerial photographs pointed out that evaporation of about $6.9 \mathrm{~mm} /$ day is reasonably expected over the Tsushima Warm Ocean Current off the coast of the Hokuriku District under a weak monsoon situation. Thus extremely dry polar air from Asian continent absorves considerable amount of moisture from the underlying warm ocean surface before reaching the coast of Japan Islands. Although most of the acquired moisture could be stored inside the atmosphere as vapor and clouds, a small portion will be returned to the sea surface in the form of over water snow showers.

The total amount of precipitation reaching

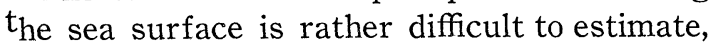
since we do not know the collection efficiency of a snow gauge on board a ship in the winter monsoon. Ishihara et. al. (1947), however, concluded that the daily precipitation beneath relatively heavy cumulonimbi would not be much. Mean precipitations measured on the off-shore islands increase toward the shore from 3 to $6 \mathrm{~mm}$ inside a $100-\mathrm{km}$ band off the coast of Honshu. The amounts measured on the island, even those with minor topography, could result in an overestimation of overwater precipitation, since a slight roughness on the islands would amplify the amount of snowfall in a manner similar to that of the lake snow frequently observed in the Great Lakes region. It would, therefore, be reasonable to assume that most of the moisture evaporated from the sea surface is transported inland across the coast line of Honshu and Hokkaido. Numerical estimates of evaporation and precipitation will be made in Section 6 .

When moist monsoon winds blow over high mountains blocking the cold air outflow at low levels, a significant unloading of moisture in the form of rain and/or snow takes place. 
Kawamura (1961 and 1964) clarified the climatological characteristics of precipitation frequencies in relation to the direction of monsoon winds as well as the orography of each island of Japan. He stressed the fact that the frequency pattern varies significantly with wind direction and that relatively small mountains, including off-shore islands, produce shadows of low frequencies extending downwind from these obstacles. On the contrary, he also found that a valley oriented in a certain direction permits the passage of monsoon clouds under favorable wind direction, resulting in a line of clouds marching downwind from the valley.

In an attempt to determine the source regions of radar echoes over the Sea of Japan, Tatehira and Fukatsu (1965) analyzed echoes photographed by a $5.7-\mathrm{cm}$ radar at Nagoya (as to the location see Fig. 3). The maximum frequencies of initial echoes were found just off the coast of Hokuriku, northwest of Nagoya, where the height of the PPI beam reaches about $2 \mathrm{~km}$. The frequencies decreased to almost zero along the range circle corresponding to a beam height of about $4 \mathrm{~km}$. Despite the fact that it is unrealistic to conclude that initial echoes do not form outside this range circle, we may postulate that the majority of the echo formations take place off the Hokuriku coast. Tatehira and Fukatsu also studied the motion of echoes in relation to winds aloft, finding that the speed as well as the direction of echo motion is very close to that of winds between 1,500 and $3,000 \mathrm{~m}$.

Fukatsu (1963) investigated organizations of snow-producing echoes by using radar data from Nagoya. In addition to longitudinal bands of echoes extending in the direction of low-level winds, he found frequent cases of transverse bands oriented perpendicular to the wind direction. Individual echoes in these transverse bands travel toward the direction perpendicular to the bands, causing their downwind displacement.

Criteria in forming either longitudinal or transverse echo bands seem to be related to the vertical wind shear within the lowest layers up to the cloud-top level. Table 1, which summarizes the vertical wind shear and the band types obtained from the radar
Table 1. Summary of band types over Hokuriku, north of Nagoya, and the vertical wind shear inside the layers below cloud tops over Wajima.

\begin{tabular}{|c|c|c|}
\hline Cases & $\begin{array}{l}\text { Vertical wind } \\
\text { shear }\end{array}$ & Band types \\
\hline Jan. 26, 1962 & 2. $0 \times 10^{-3} \mathrm{sec}^{-1}$ & transverse \\
\hline Jan. 30,1962 & 4.6 & transverse \\
\hline Jan. 13, 1963 & 4.7 & transverse \\
\hline Jan. 21,1962 & 5.0 & transverse \\
\hline Jan. 20,1964 & 5.9 & transverse \\
\hline Feb. $\quad 1,1964$ & 6.0 & longitudinal \\
\hline Jan. 12,1963 & 7.5 & longitudinal \\
\hline
\end{tabular}

pictures appearing in Fukatsu's (1963) and Tatehira and Fukatsu's (1965) papers, clearly indicates statistical evidence that transverse and longitudinal bands occur under relatively weak and strong vertical wind shears, respectively.

Change in the band structure as successive transverse bands over Hokuriku travel southeast through low valleys northwest of Nagoya is of extreme interest. Both ends of a band, extending originally over $100 \mathrm{~km}$, are cut off upon reaching the mountain ranges, thus permitting only a short segment of the band to drift over the valleys. By the time these

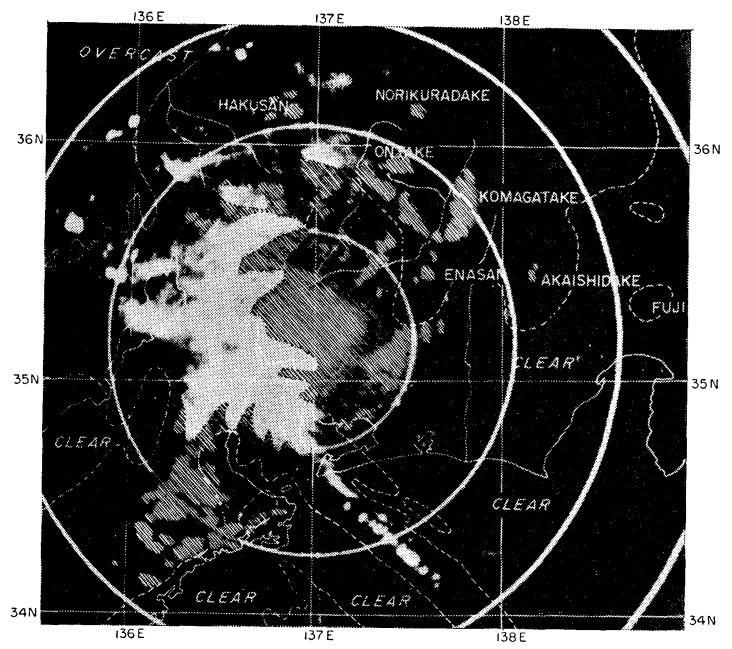

Fig. 4. Radar echoes photographed by Nagoya radar at 2340Z, Jan. 19, 1964. Estimated ground clutter is hatched. The orientation of convective clouds in a line extending southeastward from the region west of Nagoya is parallel to the prevailing northwesterly monsoon. 
short transverse bands reach Ise Bay (see Figs. 5 and 7), they appear somewhat like a series of short bands oriented in the direction of streamlines through the valleys. Formations of precipitation cells between these bands change these transverse bands into a longitudinal band extending far into the Pacific Ocean. It should be noted that the funneling effects of the valleys upon northwesterly monsoon winds would increase the wind speed considerably, resulting in a strong, vertical wind shear in the downstream regions. From this point of view, the change in the band structure can also be explained.

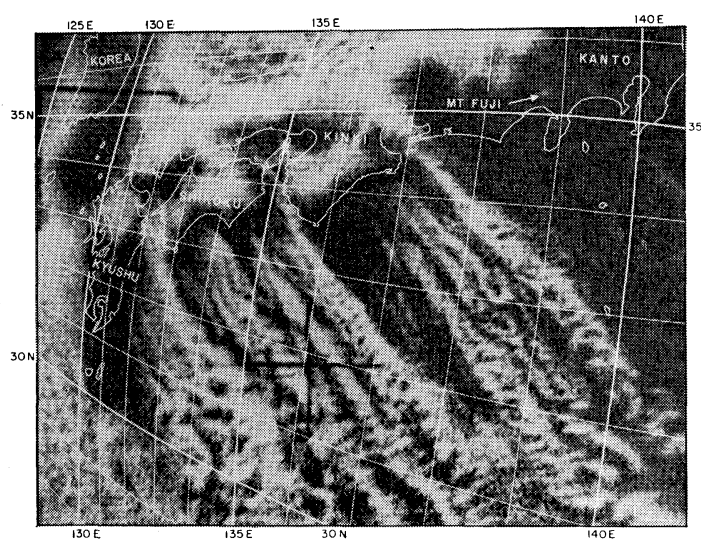

Fig. 5. A satellite photograph showing cloud bands off the Pacific coast of western Japan under the winter monsoon. Taken at 2336.5Z, Jan. 19, 1964.

An example of such a change taking place inside the effective range of the Nagoya radar was studied by using radar and satellite photographs. In order to distinguish the ground clutter from precipitation echoes, the areas of the former in the radar picture taken at 0840 JST Jan. 20, 1964 (Fig. 4) have been hatched. A satellite picture, Frame 16, Orbit 3172, TIROS VII in Fig. 5, was exposed $3.5 \mathrm{~min}$ before the radar picture, so that the pictures represent almost simultaneous views of the monsoon cloud under investigation. The patterns of the clouds in these pictures, compared with the help of geographic grids, reveal the processes by which transverse bands, some $25 \mathrm{~km}$ apart, over Hokuriku change into a longitudinal band over the Pacific. Careful comparison of echoes off the Hokuriku coast with the transverse bands in the satellite picture shows that the echoes in these bands are isolated convective towers with clear-cut boundaries, while the echoes in the bands close to or over the mountains are characterized by fuzzy edges, suggesting that they include snow falling from either anvil or shearing cloud tops. This evidence implies the rapid growth of convective elements in transverse bands as they approach the mountain ranges.

Individual echoes in the longitudinal band extending into the Pacific were located on two lines about $8 \mathrm{~km}$ apart. In view of their clear-cut, circular edges, we may postulate that these convective elements are rather young, probably forming over Ise Bay. These young clouds would transport relatively low, horizontal momentum in the subcloud layers upward, thus blocking, to a certain extent, the downwind flow of hydrometeors in successive transverse bands entering the Pacific. Both satellite and radar pictures present crescent-shaped cloud, convex upstream. We consider that successive short, transverse bands were deformed into a crescent form when their leeward movement was interrupted by the convective towers which start developing over Ise Bay. The motion of these towers determined from time-lapse radar pictures is $25 \mathrm{kt}$, while winds aloft from Hamamatsu, about $50 \mathrm{~km}$ northwest, were about $40 \mathrm{kt}$ at $850 \mathrm{mb}$. From these figures we may also expect the banding of short, transverse bands into crescent shapes.

Effects of orography upon cloud-free paths over the Pacific will be discussed in connection with the distribution of dew-point temperatures on the leeward side of the central mountains. As shown in Fig, 6, the dew point of the cold air mass entering the Sea of Japan is lower than $-20^{\circ} \mathrm{C}$. During its passage over the water, it increases gradually to about $-2^{\circ} \mathrm{C}$ along the Japan Sea coast. It is seen in the figure that the dew-point temperatures on the windward side of the mountains are rather uniform, with variations of only a few degrees. Along the leeward side, on the other hand, dew-point temperatures vary between $-15^{\circ} \mathrm{C}$ to $0^{\circ} \mathrm{C}$, relating very closely to the blocking effects of the orography. Comparison of the dew-point patterns with a satellite picture in Fig. 5 reveals 


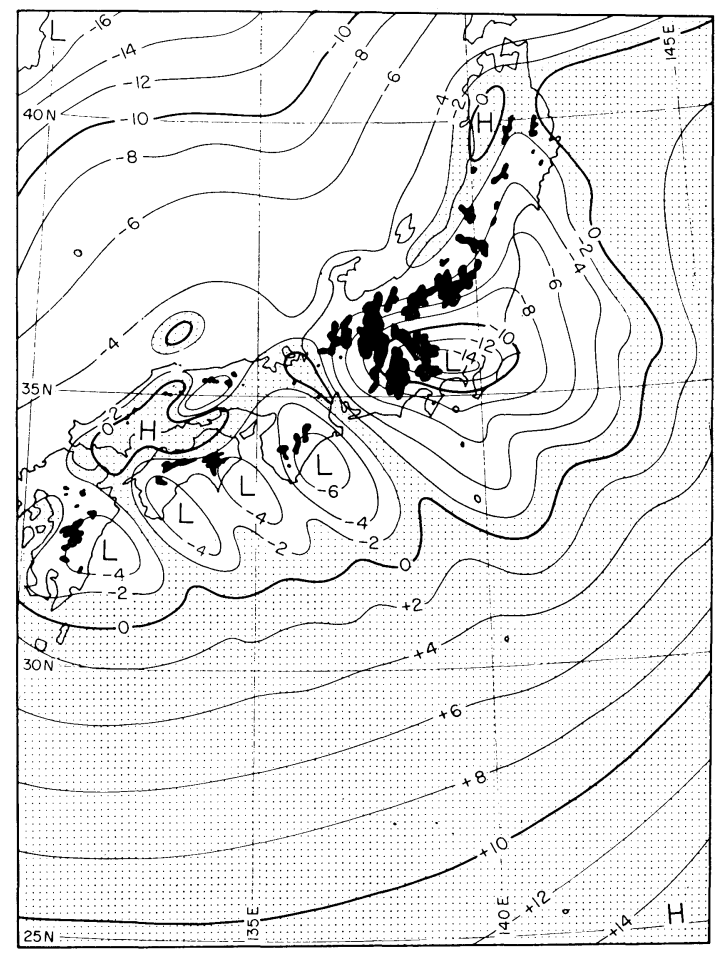

Fig. 6. Isodrosotherms for $0000 \mathrm{Z}$, Jan. 20, 1964, drawn for every $2^{\circ} \mathrm{C}$. The area above $-2^{\circ} \mathrm{C}$ is stippled. It should be noted that the pockets of low dewpoint temperature appear to the lee of high mountains which block the monsoon. Painted area indicates mountains above $1000 \mathrm{~m}$.

Table 2. Cloud-free paths and dew points to the lee of the Japan Islands. Values in the regions between the mountains are given in parentheses.

\begin{tabular}{l|rr|rr}
\hline \multicolumn{1}{c|}{ Mountains } & $\begin{array}{c}\text { Cloud-free paths } \\
\text { in km }\end{array}$ & $\begin{array}{c}\text { Dew points } \\
\text { in }{ }^{\circ} \mathrm{C}\end{array}$ \\
\hline Kyushu & 120 & $(0)$ & -5 & $(-2)$ \\
Western Shikoku & 90 & $(40)$ & -4 & $(-3)$ \\
Eastern Shikoku & 120 & $(0)$ & -5 & $(-2)$ \\
Kinki & 200 & $(0)$ & -6 & $(0)$ \\
Tokaido & 280 & $(50)$ & -10 & $(-9)$ \\
Kanto & 290 & $(70)$ & -14 & $(-8)$ \\
Tohoku & 150 & & -5 & \\
\hline
\end{tabular}

that the cloud-free path to the lee of the Japan Islands is practically zero where $T_{d}=0$. As $T_{d}$ decreases, the cloud-free path increases appreciably, reaching a measured maximum path of $290 \mathrm{~km}$ when $T_{d}$ was $-14^{\circ} \mathrm{C}$ (see Table 2). Similar orographic effects of Sikhote Alin upon cloud-free paths over the Sea of Japan would considerably alter the distance between the initial monsoon clouds and the Japan Sea coast. In order to clarify mesoscale snowfall patterns along the Japan Sea coast, it would be necessary to establish relationships between mountain ranges along the continental side of the Sea of Japan and the over-water streamlines that vary with the direction of the monsoon winds.

\section{Cloud Features in Relation to Vertical Wind Shear}

It is known that convection in the atmosphere takes place in the form of Bénard cells when the vertical wind shear within the convective layers is small. In his recent study, Hubert (1966) estimated that from 0 to $4 \mathrm{kt}$ per $1000 \mathrm{ft}\left(6 \times 10^{-3} \mathrm{sec}^{-1}\right)$ within the cloud layer and perhaps as much as $6 \mathrm{kt}$ per $1000 \mathrm{ft}$ $\left(10 \times 10^{-3} \mathrm{sec}^{-1}\right)$ across the cloud base would be small enough to permit three-dimensional cellular convection. When these shear values are averaged over the entire depth of conve, tion, a mean shear of less than 7 or $8 \times 10^{-3}$ $\mathrm{sec}^{-1}$ would be required for the cellular convection. Our estimate indicated that the upper limit of the shear is in reasonable agreement with Hubert's result, considering the difficulties in determining the shear. With increasing shear, the tilt of these cell axes becomes so large that the cellular convection gradually changes into transverse rolls, commonly observed under moderate wind shear. Aerodynamical experiments by Chandra (1938), who used smoke as a flow indicator, revealed the transitions from open cells to transverse rolls and finally to longitudinal bands when the vertical wind shear was increased.

For verification of these transitions, a series of satellite pictures, taken at $30-\mathrm{sec}$ intervals by TIROS VII in Orbit 3172 , provided excellent patterns of convective clouds embedded in the layers of varying vertical wind shear. The composite cloud chart in Fig. 7 shows the patterns within a few minutes of 0836 JST, Jan. 20, 1964. The vertical wind shear, defined as the mean vertical wind shear between the surface and 


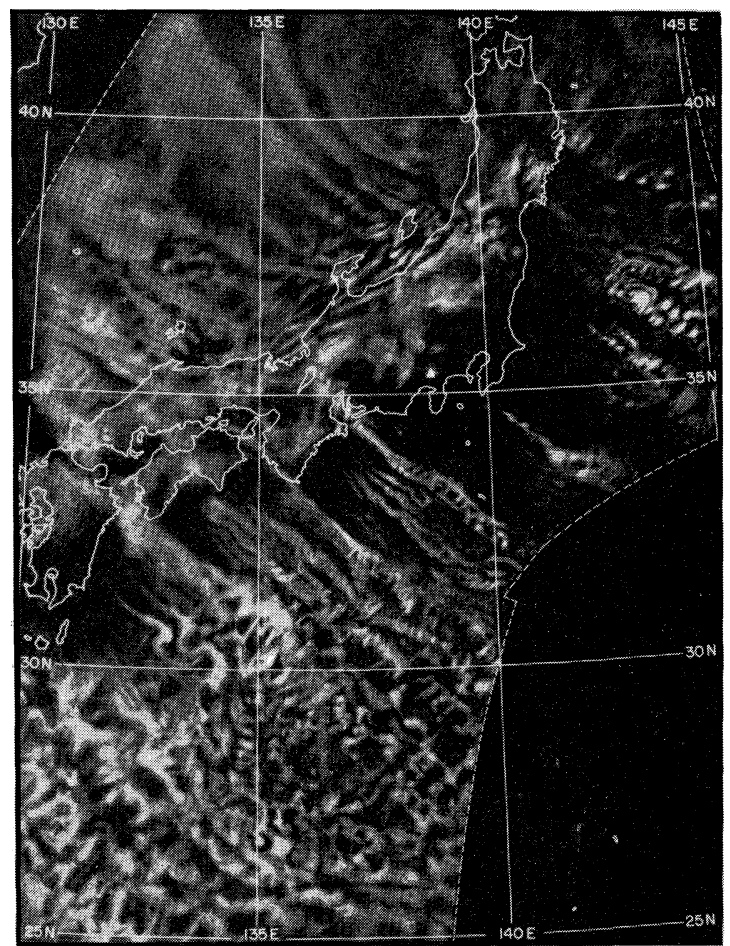

Fig. 7. A composite cloud chart constructed from three gridded pictures of TIROS VII, exposed between 2335.5 and 2337.5Z, Jan. $19,1964$.

the top of convective clouds, was computed at each upper-air station in order to obtain. the shear chart for 0900 JST, Jan. 20, 1964 (Fig. 8). Included in the figure are the isolines of computed shears drawn for every $2 \times 10^{-3} \mathrm{sec}^{-1}$, height contours of the $850-\mathrm{mb}$

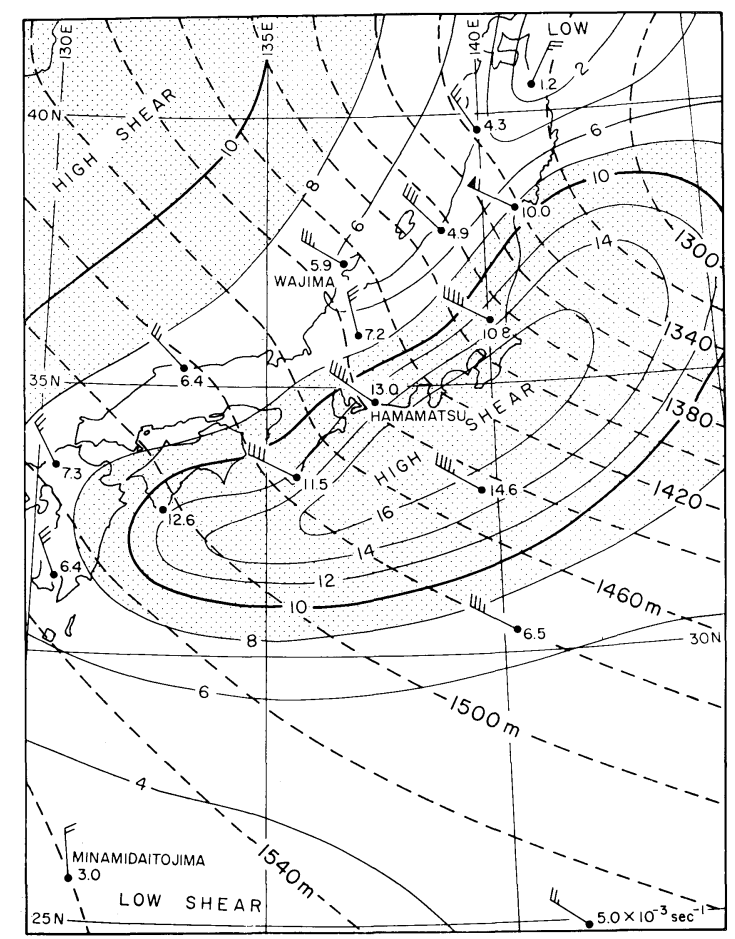

Fig. 8. Isolines of vertical wind shear drawn on an $850-\mathrm{mb}$ chart at $0000 \mathrm{Z}$, Jan. 20, 1964 The number by each wind symbol denotes the mean vertical wind shear in $10^{-3} \mathrm{sec}^{-1}$. Solid lines indicate the shear contoured for every $2 \times 10^{-3} \mathrm{sec}^{-1}$, and broken lines are height contours drawn for every $20 \mathrm{~m}$. The fractional barbs are drawn in such a way that the length is proportional to the wind speed above the multiple of $10 \mathrm{kt}$.
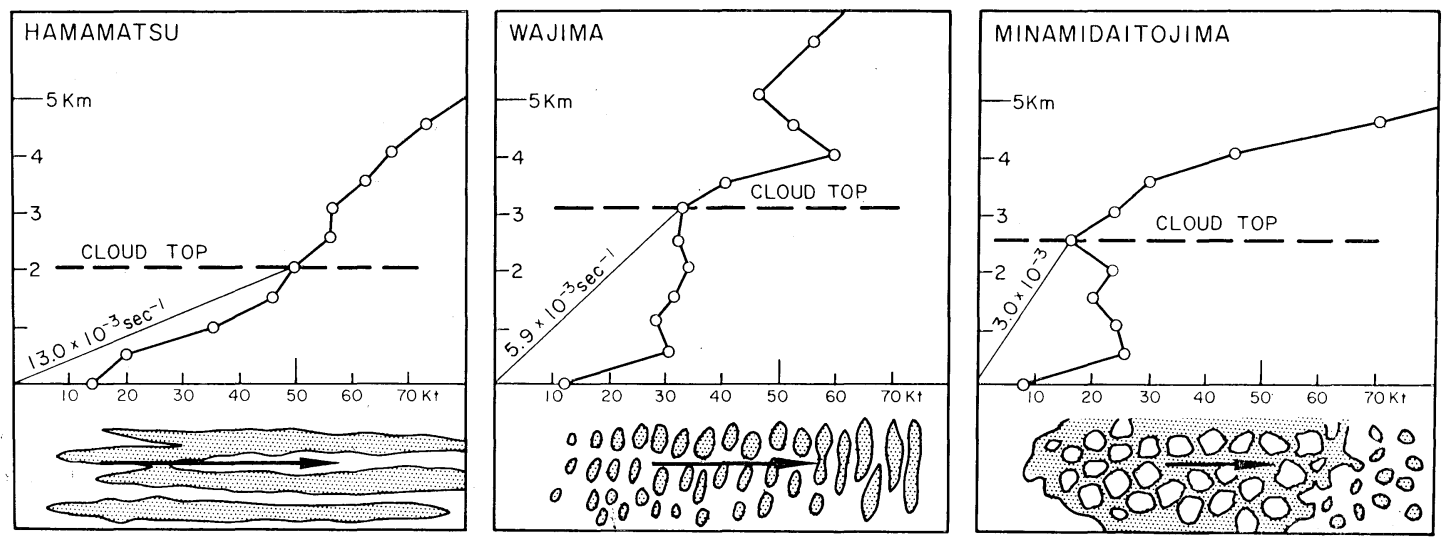

Fig. 9. Wind profiles corresponding to the longitudinal (left), transverse (middle), and cellular (right) convective regimes. Vertical wind shear values were computed between the cloudtop wind and the surface wind which was assumed to be zero. 
surface shown in dashed lines, 850-mb winds expressed in full barbs, each representing $10 \mathrm{kt}$, and a fractional barb with its length proportional to the wind speed below $10 \mathrm{kt}$.

Wind profiles from three upper-air stations located in typical regions of strong, moderate, and weak wind shears are presented in Fig. 9. The top of convective clouds at each station is given in dashed lines. As in other cases, the winds aloft measured at these stations increased rapidly inside the subcloud layers. Within the layers of monsoon clouds, the shear decreases considerably, probably due to mixing processes above the lower boundary layers. It is commonly observed that a rapid increase in wind speed occurs immediately above the height of the cloud tops. The mean vertical wind shear below the cloud-top height, $\bar{S}$, was determined in this paper by drawing a straight line connecting the origin, or zero wind speed at the surface, with the wind speed at the cloud top. The reason for using the origin without using the wind measured in the lowest level above the surface is the variability of the latter wind, due to its fluctuation and to local topography.

Careful comparison of Figs. 7 and 8 permits us to determine the criteria of vertical wind shears which determine three convection regimes mentioned above. First of all, an interpolated isoline of $\bar{S}=5 \times 10^{-3} \mathrm{sec}^{-1}$, extending from south of Kyushu eastward, seems to represent the northernmost limit of the area of cellular convection. Within this area, however, more regular cells are found toward the southwest corner of the chart, toward which the shear decreases gradually.

Longitudinal bands of clouds are seen predominantly off the Pacific coast of Japan where $\bar{S}$ exceeds approximately $7 \times 10^{-3} \mathrm{sec}^{-1}$, with the exception of a small area near the northeast corner affected by a cyclone, east of Tohoku. It should be noted that the larger the shear, the more, significant the longitudinal bands. Even though high nadir angles of view do not clearly show the mode of convection over the Sea of Japan, high shear values above $7 \times 10^{-3} \mathrm{sec}^{-1}$ suggest that it will be in a longitudinal mode. Cloud patterns in Fig. 3 , developing under almost identical shear on a different day, are longitudinal and approximately parallel to the 850 -mb contours. Note also that the orientation of the longitudinal bands in Fig. 7 is in line with the $850-\mathrm{mb}$ contours.

Inside the narrow zones bounded by the isolines of $\bar{S}=5$ and $7 \times 10^{-3} \mathrm{sec}^{-1}$, there must be a transition between longitudinal bands and cellular clouds, Careful examination of such a zone extending eastward from south of Kyushu in Fig. 7 suggests a transition process in which the longitudinal bands widen and merge. These wide bands then break up into short rolls perpendicular to the flow direction. The transverse bands thus created gradually lose their transverse characteristics as they move into the region of weak shear, finally changing into cellular clouds south of the shear contour, $S=5 \times 10^{-\overline{3}} \mathrm{sec}^{-1}$.

The change in the shear when the monsoon air moves over Japan decreases the shear below the critical value, $\bar{S}=7 \times 10^{-3} \mathrm{sec}^{-1}$. If we examine the change in the convection regimes along the streamlines across Japan, it will be found that the longitudinal bands over the Sea of Japan break up into transverse bands of various lengths and widths as they approach the central mountains. The average width between the major cloud band axes off the coast of the Hokuriku District is $26 \mathrm{~km}$ in this case. As these bands cross the mountains, development of new formations of longitudinal bands takes place inside the region of strong shear.

Returning to Fig. 9, we shall elaborate on the effects of vertical wind shear upon convection regimes. According to Kuettner's (1959) study on the formation of longitudinal cloud bands, closely related to the curvature in the profile of non-veering winds aloft, the existence of a significant curvature, in the order of $-10^{-7} \mathrm{~cm}^{-1} \mathrm{sec}^{-1}$, would be necessary for the initiation of longitudinal bands. A few years later, Higuchi (1963) attempted to explain the mechanism of longitudinal band-formation over the Ishikari Plain in Hokkaido on the basis of Kuettner's idea, reaching fairly good agreement with what was suggested. Winds aloft from three stations in Fig. 9, as well as from other station data on Jan. 20, 1964, and also the other data of winter monsoon case indicated, however, that the convection regimes were related more closely to the mean wind shear 
than to the curvature, thus necessitating further consideration of the conditions required for the formation of longitudinal bands.

If we accept Kuettner's concept that a restoring force exerting a lineating effect on convection is needed for the formation of longitudinal rolls, a dynamical, restoring force, appearing when an air parcel oscillates through a layer of significant curvature, would play an important role. On the other hand, a similar restoring force can be supplied through a stable density stratification commonly observed near the tops of the winter monsoon clouds. Such a stratification is not a pre-existing atmospheric structure, as in the case of Kuettner's (1959) and Higuchi's (1963) prerequisite conditions, created by low-level friction and high-level, thermal winds. As a result of cloud-scale turbulence initiated through heating and moisture supply from an underlying warm water surface, a layer of tight gradient in potential temperature tops the cloud layer, giving rise to a restoring force against the vertical penetrations of convective elements, It would be reasonable to consider that a restoring force created through the dynamical and thermodynamical nature of the monsoon atmosphere in addition to shear effect contributes to the lineating effects under consideration.

Based on analyses of the Nagoya radar and satellite pictures, it seems reasonable to postulate that a convective cloud which happens to develop inside a region of vertical wind shear partially blocks the monsoon winds near the cloud-top levels. Existence of crescent-shaped clouds and echoes, already pointed out in Fig. 4 and 5, positively indicates the deformation of flow caused by a convective cloud that transports upward the small horizontal momentum in the subcloud layers. The vertical wind shear to the lee of the convective cloud would, therefore, be considerably smaller than that along the streamlines on both sides of the cloud. The excessive shear thus created would quickly shear off newly forming convective elements before developing into clouds. As a result, the most favorable location for new cloud development would be just behind the already existing cloud. If we move away from the streamlines through a longitudinal band, there are locations on both sides of the band that would permit new cloud formations. For these reasons, periodic longitudinal bands separated by cloud-free bands are the only mode of convection developing under a large vertical wind shear.

From these analyses and considerations we shall summarize the criteria of vertical wind shear corresponding to three convection regimes in the winter monsoon:

$0<\bar{S}<5 \times 10^{-3} \mathrm{sec}^{-1}$ cellular clouds

$5 \times 10^{-3}<\bar{S}<7 \times 10^{-3} \mathrm{sec}^{-1}$ transverse bands

$\infty>\bar{S}>7 \times 10^{-3} \mathrm{sec}^{-1} \quad$ longitudinal bands.

These criteria are in rather good agreement with the band types of radar echoes presented in Table 1. It should also be noted that the mean shear over the Great Lakes region, corresponding to the satellite picture in Fig. 1 , was $8.4 \times 10^{-3} \mathrm{sec}^{-1}$, which would give longitudinal bands as seen in the picture. Care must be taken, however, that the criteria are valid for a rather uniform wind direction between the lower boundary and the cloud top.

\section{Estimate of Total Water Content from Satellite Aerological Data}

We have discussed the cloud formation over the Sea of Japan and the Pacific Ocean occurring under the influence of the winter monsoon. In order to compute the water budget associated with the cold-air outbreak, the authors attempted to use radiation data obtained by meteorological satellites.

For an estimate of such water budget, the contribution of hydrometeors, including both liquid and ice phases of incloud water, was long neglected until Ninomiya (1964) tried to apply an estimated liquid-water content of $0.43 \mathrm{~g} \cdot \mathrm{kg}^{-1}$ within the overcast regions, assumed whenever the relative humidity exceeds $85 \%$.

Taking advantage of satellite radiation data, a reasonable estimate of cloud cover was made by the authors in an attempt to compute the total water budget, including clouds. The precipitable water inside the air column free from cloud is expressed by

$$
Q_{0}=-\frac{1}{g} \int_{P_{0}}^{P_{m}} q_{a} d P \cong-\frac{1}{g} \int_{P_{0}}^{P_{m}} r_{a} d p
$$



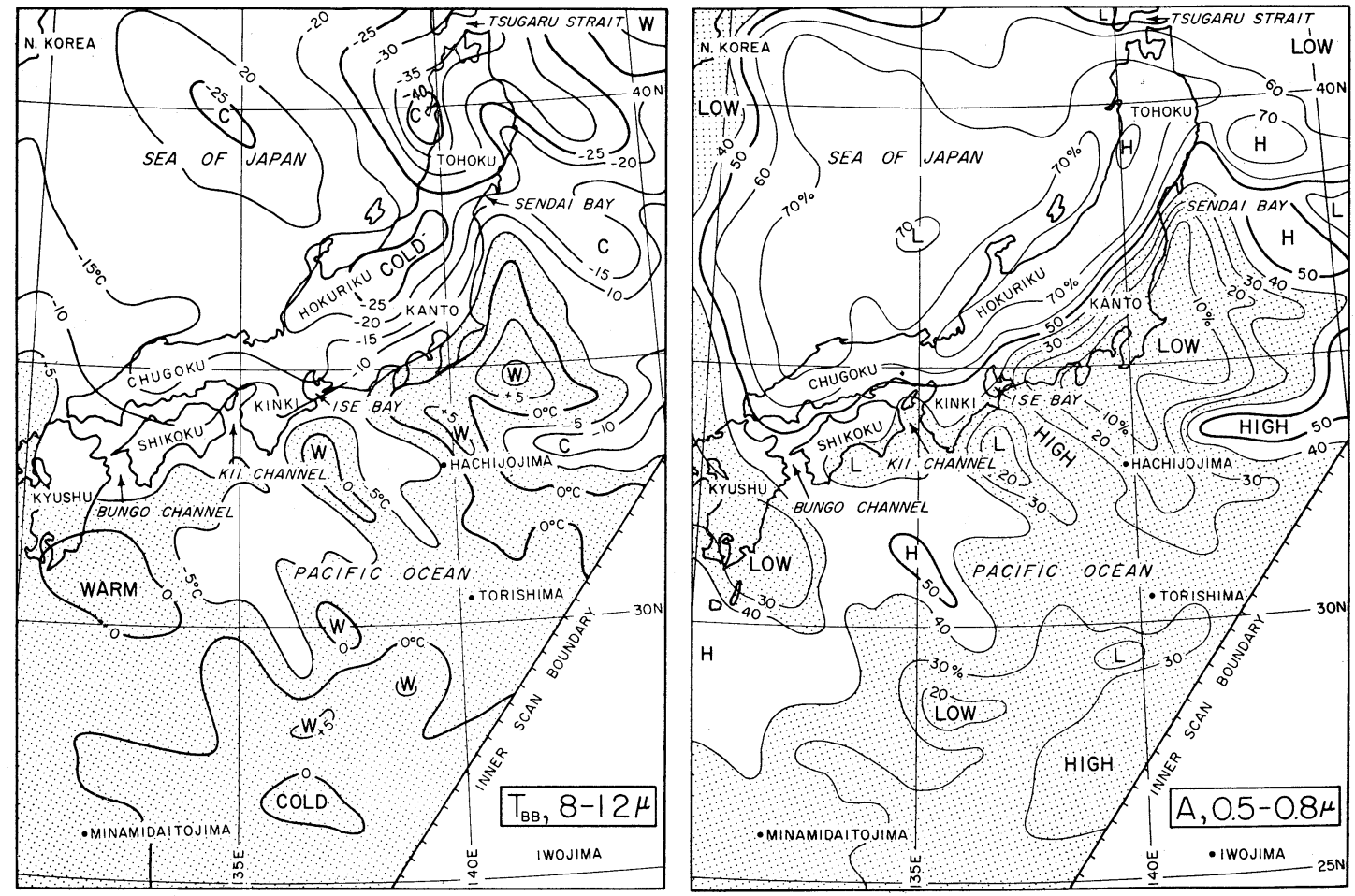

Fig. 10. Isotherms of equivalent blackbody temperatures obtained from TIROS VII, Channel 2 data (left) and albedoes from Channel 5 data (right). Scanning was made between 2333 and 2338Z, Jan. 19, 1964, when the satellite pictures used in constructing the composite cloud pattern in Fig. 7 were taken.

where $q$ denotes the specific humidity; $r$, the mixing ratio; $P_{0}$ and $P_{m}$, pressures at the surface and the monsoon top; and the suffix. $a$, refers to the cloud-free air.

In the actual computation of $Q_{a}, P_{m}$ was assumed to be $500 \mathrm{mb}$ since specific humidity above this level is extremely small, while $P_{t}$ is decided from aerological data and IR analyses. Likewise, the precipitable water and hydrometeors inside an air column containing clouds are written as

$$
Q_{c} \cong-\frac{1}{g} \int_{P_{0}}^{P_{b}} r_{s} d P-\frac{1}{g} \int_{P_{b}}^{P_{t}}\left(r_{i}+r_{w}\right) d P
$$

where suffixes, $c, b, s, t, i$, and $w$ refer to cloud, cloud base, subcloud, cloud top, incloud, and water, respectively. The quantity, $Q_{c}$, designating the mass of water in all forms over the unit area is called the "total water."

For most convective clouds, we may consider that $r_{s}$ is constant and that $r_{i}$ decreases upward, following the moist adiabat extrapolated from the cloud base. The adiabatic liquid plus the solid water content (LWC), defined by

$$
r_{w}^{*}=r_{b}-r_{i}
$$

is usually larger than the actual LWC, due mainly to the entrainment in small clouds and to precipitation in the case of large, convective clouds. According to Neiburger (1949), the LWC of California stratus increases upward almost in proportion to the height above the cloud base, thus keeping the relative water content, expressed by $r_{m} / r_{w}^{*}$, at a constant value of about 0.7 from the cloud bases to a little below the cloud tops at about $600 \mathrm{~m}$. For most low, convective monsoon clouds, the relative water content within the layers several hundred meters above the cloud base may be considered constant. According to Ninomiya's (1964) estimate, based on Ackerman (1959), Squires (1958), and Warner (1955), the relative water content decreases exponentially as the height increases, reaching about 0.2 at the $3-\mathrm{km}$ 
level. We shall now define the precipitable water and the LWC inside an air column containing clouds, nothing that $r_{s}$ is constant and $r_{1}+r_{w}=r_{b}=r_{s}$. Eq. (2) thus permits us to write

$$
Q_{c}^{*} \cong \frac{r_{s}}{g}\left(P_{0}-P_{t}\right)
$$

where $Q_{c}^{*}$ is called the "adiabatic total water."

It is important to note that both $Q_{0}$ and $Q_{c}$, as well as $Q_{c}^{*}$ with a unit, $\mathrm{gr} \cdot \mathrm{cm}^{-2}$ or $\mathrm{mm}$, are quantities varying with geographic location. Because the distribution of clouds in microscale is so variable. It is necessary to discuss their smoothed patterns by defining a quantity averaged over the area of cloudcover measurement. This quantity, defined by

$$
\bar{Q}=n Q_{c}+(1-n) Q_{a}
$$

where $n$ denotes the cloud cover obtained from satellite data, is called the "averaged total water" with the unit, $\mathrm{gr} \cdot \mathrm{cm}^{-2}$ or $\mathrm{mm}$.

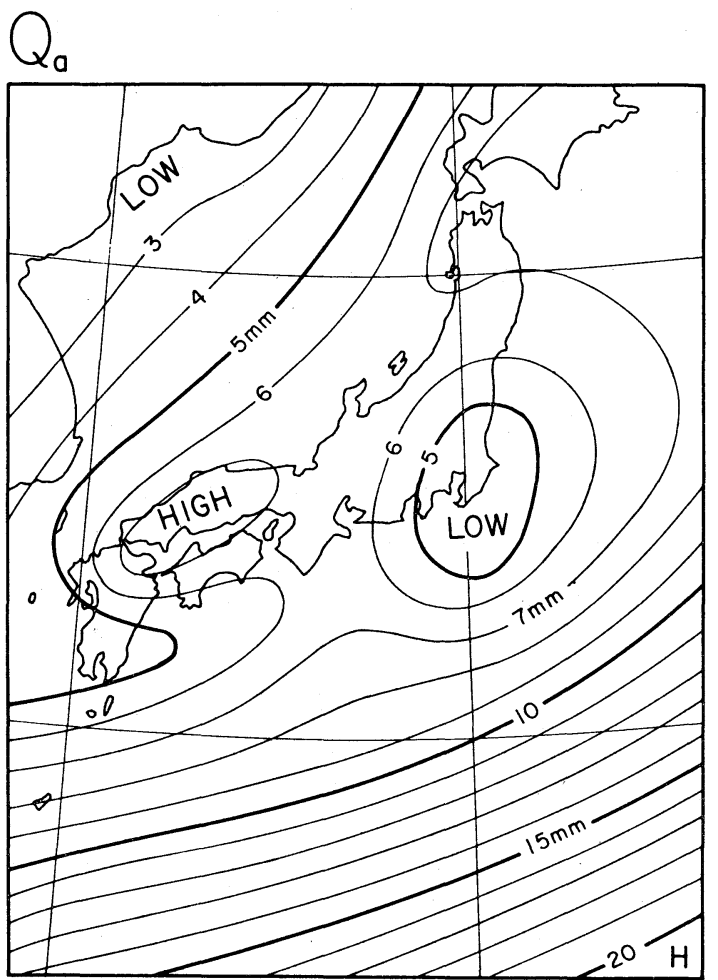

$Q_{c}$ and $Q_{a}$ are constants within the area of fractional cloud cover, $n$, and the cloud-free area, $(1-n)$. Cloud covers in this paper were computed within semi-rectangular areas formed by one-degree longitudes and latitudes, so as to compute $\bar{Q}$ for each of these areas.

The right side of Eq. (5) can also be expressed by using $Q_{c}^{*}$ instead of $Q_{c}$. When $Q_{c}^{*}$ is used, the cloud cover, $n$, must decrease to $n^{*}$ in order not to alter the averaged total water, $\bar{Q}$. Thus we have

$$
\bar{Q}=n^{*} Q_{c}^{*}+\left(1-n^{*}\right) Q_{a}
$$

where $n^{*}$ is called the "equivalent adiabatic cloud cover." From a physical point of view, $n^{*}$ may be considered as the cover of adiabatic clouds replacing actual clouds without changing the averaged total water. With the use of a ratio,

$$
k=n^{*} / n
$$

Eq. (5) can now be written as

$$
\bar{Q}=k n Q_{c}^{*}+(1-k n) Q_{a}
$$

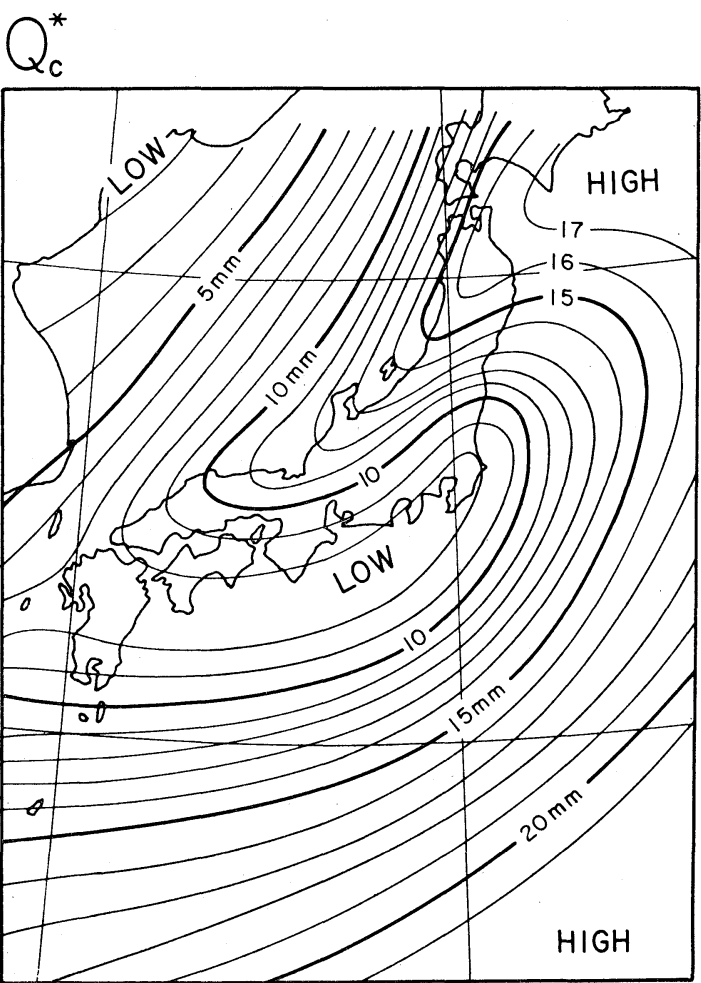

Fig. 11. Distribution of precipitable water (left) and adiabatic total water (right) given by contour lines drawn at intervals of $1 \mathrm{~mm}$. Map time: 0000Z, Jan. 20, 1964. 
If we can make a reasonable estimate of $k$, this equation will permit us to compute total water from satellite and aerological data. Note that $Q_{c}^{*}$ in Eq. (4) and $Q_{a}$ in Eq. (1) can be determined from aerological data.

Computation of $n$ from satellite data has been extensively discussed by Fujita and Grandoso (1965). Due to the fact that relative whiteness as defined in this paper is very close to 1.0 for winter monsoon clouds and that the clouds are relatively low, a simplified formula,

$$
n=\frac{\bar{A}-\bar{A}_{b}}{\bar{A}_{c}-\bar{A}_{b}}
$$

where $\bar{A}, \bar{A}_{b}$, and $\bar{A}_{c}$ are the measured, back ground, and cloud albedoes, respectively, was used in our present computation. An albedo chart (Fig. 10, right), contoured at $10 \%$ intervals, shows that $8 \%$ albedo for the overwater background and $80 \%$ for extensive cloud areas are reasonable values for use in Eq. (9). The left chart in Fig. 10 gives isotherms of equivalent blackbody temperatures measured by the TIROS VII window channel. The coldest area off the Tohoku coast, with $-40^{\circ} \mathrm{C}$ temperature, would represent cloud tops reaching as high as $500 \mathrm{mb}$; and two areas surrounded by the $-25^{\circ} \mathrm{C}$ isotherm would indicate cloud tops at about $650 \mathrm{mb}$.

Presented in Fig. 11 are the patterns of the precipitable water, $Q_{a}$, and the adiabatic total water, $Q_{c}^{*}$. In computing the mean total water, $\bar{Q}$, from Eq. (8), we assumed an extreme case where $k=1.0$, knowing that this assumption would over-estimate $\bar{Q}$ when the cloud covers (Fig. 12) computed from Eq. (9) were used. Nevertheless, the pattern of $\bar{Q}$, thus computed and presented in Fig. 12, indicates an extreme case when the entire area of clouds viewed from a satellite consists of convective clouds with adiabatic total water. After developing more formulae necessary for water-budget estimates, we shall discuss in detail the effects of $k$ upon
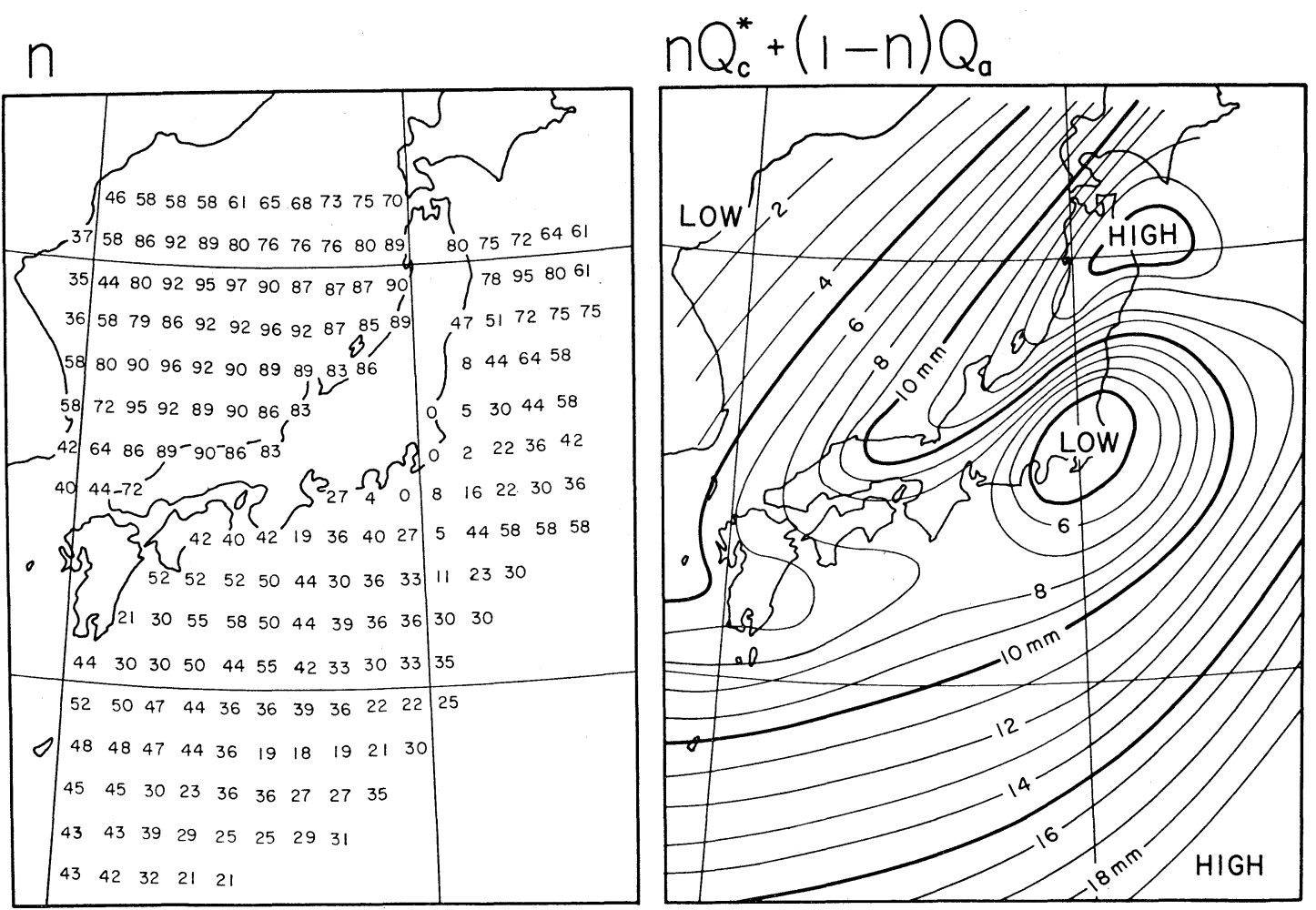

Fig. 12. Cloud covers in percent computed from albedo values appearing in Fig. 10 (left) and adiabatic total water (right), both contoured at 1-mm intervals. Map time : 2333-2338Z, Jan. 19, 1964 (left); 0000Z, Jan. 20, 1964 (right). 
the determination of evaporation and precipitation.

\section{Evaporation and Precipitation Computed from Averaged Total Water}

The previous section discussed the computation of the averaged total water, $\bar{Q}$, from satellite and aerological data. Because of rather uniform wind velocities along the vertical between the tops and bases of monsoon clouds, we may reasonably assume that water vapor evaporated from the sea surface is stored inside an air column traveling with the mean monsoon winds. Based upon this and steady state assumption, we compute the vertical flux of water through the sea surface as the difference between outgoing and incoming total water through vertical walls above the boundary of an area element at the sea level. We now consider two streamlines separated by $\alpha$, which varies with $\beta$, the distance measured downwind along the streamlines. The incoming flux of total water through the upstream wall perpendicular to the flow,

$$
M_{\text {in }}=\bar{Q} \bar{V} \alpha
$$

where $\bar{V}$ denotes the mean wind speed through the wall, is subtracted from that through the downstream wall perpendicular to the flow,

$$
M_{\mathrm{out}}=\bar{Q} \bar{V} \alpha+\frac{\partial \bar{Q} \bar{V} \alpha}{\partial \beta} d \beta
$$

to obtain the moisture transport through the unit area on the sea surface. Thus

$$
\begin{aligned}
\frac{M_{\text {out }}-M_{\text {in }}}{\text { area element }} & =\frac{1}{\alpha} \cdot \frac{\partial M}{\partial \beta}=\bar{Q} \frac{1}{\alpha} \frac{\partial \bar{V} \alpha}{\partial \beta}+\bar{V} \frac{\partial \bar{Q}}{\partial \beta} \\
& =\bar{Q} \nabla \cdot \bar{V}+\bar{V} \cdot \nabla \bar{Q}=\operatorname{div} \bar{Q} \bar{V}
\end{aligned}
$$

where $M=\bar{Q} \bar{V} \alpha$ represents the total water flux between two streamlines. Eq. (12) represents the well-known expression of water divergence integrated over the monsoon layers modified by the moisture and heat transported from the sea surface. Since the moisture transport from the sea (or land) surface occurs in the form of evaporation and precipitation, we finally write

$$
\operatorname{div} \bar{Q} \bar{V}=E-R
$$

where $E$ and $R$ denote, respectively, the evaporation and precipitation from unit area per unit time. They may be expressed in the unit of $\mathrm{gr} \cdot \mathrm{cm}^{-2} \mathrm{day}^{-1}$, or $\mathrm{mm} \cdot \mathrm{day}^{-1}$.

Presented in Fig. 13 are the isolines of $E-R$ computed from Eq. (13) by using the averaged total water, $\bar{Q}$, and the mean wind speed, $\bar{V}$. It will be found that the rate, $E-R$, over the Pacific southeast of Honshu exceeded $40 \mathrm{~mm} \cdot$ day $^{-1}$, while the maximum rate over the Sea of Japan was less than 30 $\mathrm{mm} \cdot \mathrm{day}^{-1}$. If we assume that little or no precipitation occurs over these areas, $E-R$ represents the rate of evaporation from the sea surface. Over the islands of Japan, on the other hand, $E-R$ consistently showed negative rates, suggesting that they represent the precipitation rates over the islands.

Since the results obtained so far were computed by using the averaged total water, $\bar{Q}$,

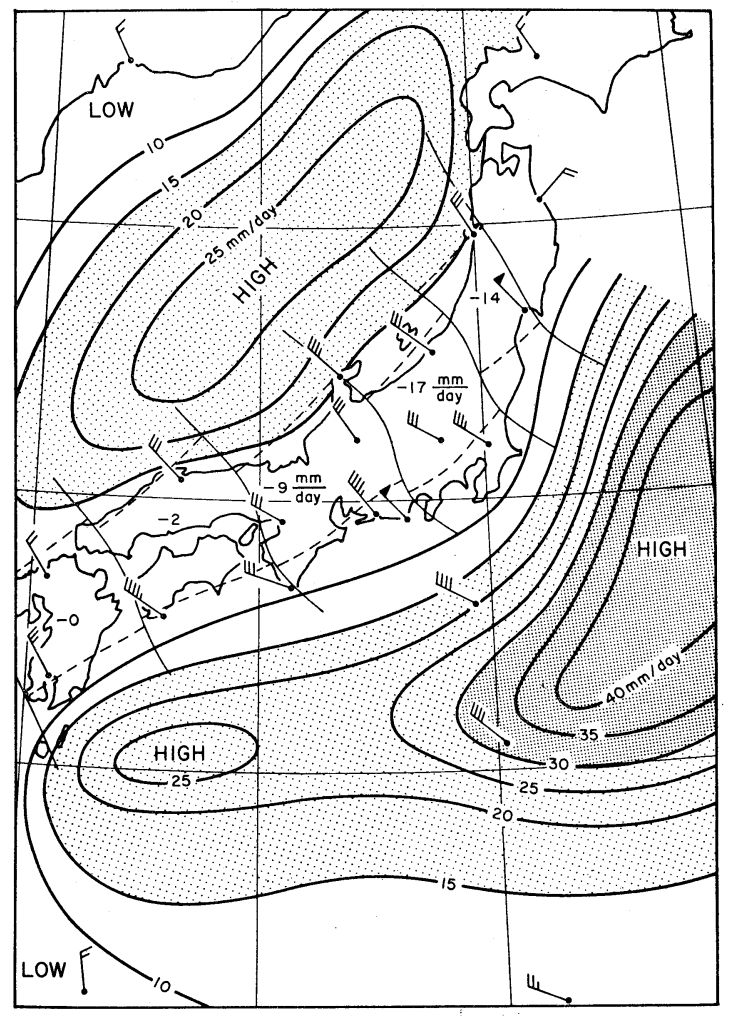

Fig. 13. Divergence of total water content computed by assuming $k=1.0$. Wind symbols designate the mean wind speeds used in the computation. 


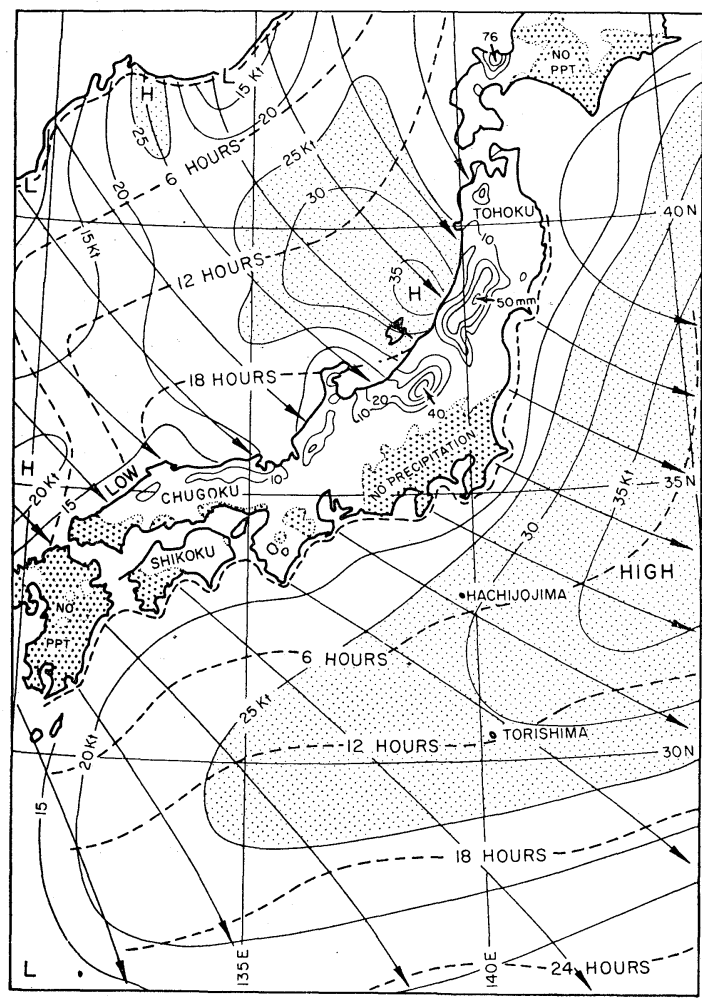

Fig. 14. A map showing isolines of daily precipitation, isotachs, and streamlines of surface winds. The region above $25 \mathrm{kts}$ is stippled. The dotted lines indicate the leading edges of the surface air at six-hour intervals after leaving the Pacific coast of Japan and the Sea of Japan coast of Siberia. The stippled area over the land is the area without precipitation during the previous 24 hours. Map time: 0000Z, Jan. 20, 1964.

defined by Eq. (8), while assuming $k=1.0$, they could be way off from the actual values if $k$ is other than 1.0. In view of the fact that most clouds are characterized by a por tion of adiabatic total water, it would be reasonable to consider $k$ as smaller than 1.0.

The actual rainfall over Japan, as shown in Fig. 14, was as little as several millimeters per day when averaged over the island area. The computed rainfall over central Honshu was $17 \mathrm{~mm} \cdot$ day $^{-1}$, which could be several times larger than the actual amount, thus necessitating the use of proper values of $k$ instead of 1.0 .

In order to evaluate the computed evaporation over the water surface, the streamlines and isotachs in Fig. 14 and the isodrosotherms in Fig. 6 were used in determining the evaporation rate from Jacobs' equation,

$$
E=0.143\left(e_{s}-e_{a}\right) V_{s}
$$

where $E$ gives the evaporation rate in $\mathrm{mm}$. day $^{-1} ; e_{s}$, the saturation vapor pressure (in $\mathrm{mb})$ at the sea-surface temperature; $e_{a}$, the vapor pressure of the air above the sea surface; and $V_{s}$, the wind speed (in $\mathrm{m} \cdot \mathrm{sec}^{-1}$ ) measured on board ship. The evaporation rates thus obtained from Jacobs' equation for a case of a strong cold air outbreak of Jan. 20, 1964 were contoured for every $5 \mathrm{~mm} \cdot$ day $^{-1}$ in Fig. 15, which also includes isotherms of the sea-surface temperatures used in computing $e_{s}$. The rather large values are due to strong winds and low dew points. The values of $|V| \cdot\left(e_{s}-e_{a}\right)$ for this day was twice as large as those of the monthly mean.

Comparison of the evaporation rates in

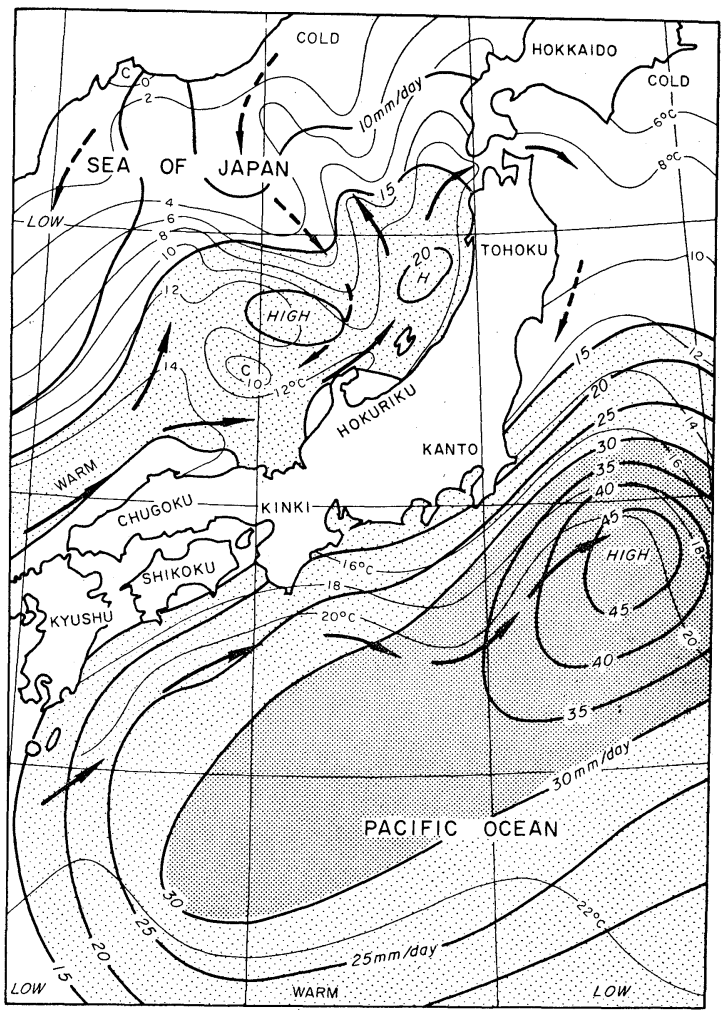

Fig. 15. Estimated sea-surface temperature in ${ }^{\circ} \mathrm{C}$, ocean currents, and daily evaporation in $\mathrm{mm}$ computed from Jacobs evaporation equation. Thick arrows indicate the warm ocean currents and dotted arrows, the cold ocean currents. 


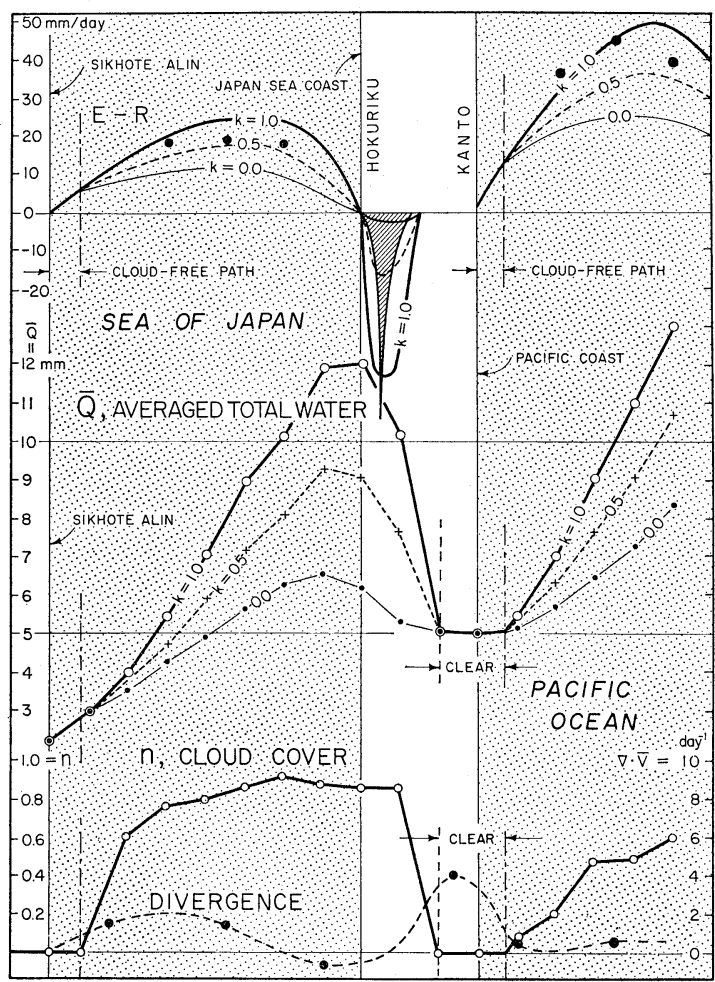

Fig. 16. The total water content (middle); its divergence (upper) computed for the three values of $k=0,0.5$, and 1.0 ; and the cloud cover and divergence. All were obtained along a band extending from near Vladivostok to the Pacific through the Hokuriku and Kanto districts. Actual precipitation measured over Hokuriku is shown by a hatched area.

Fig. 13 and 15 and of the precipitation rates in Fig. 13 and 14 indicates conclusively that the values of $-R$ and $E$ in Fig. 13, computed from Eq. 13, are too large to be realistic, thus necessitating the determination of values of $k$ properly applicable to winter monsoon clouds.

For the purpose of evaluating $k$, two streamlines extending from the Siberian coast to Hokuriku, Kanto, and to the Pacific were selected. Then the averaged total water, $\bar{Q}$, was determined from Eq. (8) by changing $k$ into five values, $0.00,0.25,0.50,0.75$, and 1.00. The middle curves in Fig. 16 represent variations of $\bar{Q}$ corresponding to $k=0.0,0.5$, and 1.0. It is obvious that the averaged total water for $k=0.0$ indicates the precipitable water which is not affected by clouds. As $k$ increases to 1.0, the contribution of incloud water to the averaged total water increases to a maximum, which occurs when the total area of satellite-measured clouds is assumed to be of adiabatic total water. The variations in $\bar{Q}$ along the streamlines under consideration, therefore, are most significant when $k=1.0$, increasing from 2 to $12 \mathrm{~mm}$ during the passage over the Sea of Japan. Only one-third of this variation takes place when $k=0.0$. Using these curves of $\bar{Q}$ and $\nabla \cdot \bar{V}$, shown in the lower curve in Fig. 16, divergence values of $\bar{Q} \bar{V}$ were computed in order to plot them against the distance along the streamlines.

The top curves in Fig. 16 present the variation of divergence values, or $E-R$, corresponding to $k=0.0,0.5$, and 1.0. Six black dots in the Sea of Japan and the Pacific Ocean represent values computed from Jacobs' equation, Eq. (14). From this result, it is likely that $k$ over the Sea of Japan is about 0.6 on the average, while over the Pacific it is about 0.8 on the average.

Of interest is the effect of $k$ upon the precipitation over Hokuriku. The figure reveals that the flux, $-17 \mathrm{~mm} \cdot \mathrm{day}^{-1}$, occurring when $k=1.0$, changed to about $-1 \mathrm{~mm} \cdot$ day $^{-1}$ when $k=0.0$. The rate of actual precipitation measured along the streamlines, shown as a hatched area, indicates that the proper value of $k$ over Hokuriku would be about 0.6.

From this evidence it may be concluded that $k$ was about 0.6 over the area of the Sea of Japan and that it increased to about 0.8 over the Pacific Ocean.

\section{Conclusions}

Through the effective use of satellite data it was confirmed that cloud formation and distribution under the winter monsoon are greatly influenced by topographical features.

It was found that the cloud-free paths are in the order of 10 to $50 \mathrm{~km}$ when there is a very fresh outbreak of cold, polar continental air from the Siberian coast. With a weakening monsoon, the paths increase to over 400 $\mathrm{km}$ without permitting convective clouds to form off either the west coast of Sakhalin or Hokkaido.

Obtained criteria of the mean vertical wind shear, corresponding to the cloud patterns of 
three convective regimes (cellular, transverse, and longitudinal), under the condition of a rather uniform wind direction from the lower boundary to the cloud top seem in good agreement with those appearing in satellite pictures and with the patterns of radar echoes. In regard to a mechanism of the formation of longitudinal cloud bands, several considerations should be taken into account. Since the mean shear is closely related to the cloud pattern, the restoring force supplied through a stable density stratification, commonly observed near the tops of winter monsoon clouds, as well as that due to the shear gradient proposed by Kuettner to explain the lineating effects of convective clouds, needs to be emphasized.

The method developed by the authors, which involves a few assumptions, can be effectively used to compute the average cloud coverage over the ocean or land with small and uniform albedoes. It was found that the water content of convective clouds under the winter monsoon is considerably smaller than that obtained through adiabatic processes. It can also be concluded that the total water content, including that of the cloud, can be effectively used for precipitation forecast as well as evaporation computation.

Through proper uses of radiation measurements, pictures taken from weather satellites, and other observation data, constants involved in evaporation or diffusion equations can also be obtained with fair accuracy. In this connection, further improvements in radiation data reduction and sensors and simultaneous radiation measurements with radio-sounding observations are desirable.

\section{Acknowledgments}

The authors wish to express their appreciation to Messrs. Tansen Ishida, Tsugio Matsumoto, Narimasa Tajima, and Fukutaro Shinshi for their helpful suggestions regarding seasurface temperature and maritime weather conditions and to Kenji Ishihara for his comments concerning weather and maritime conditions over the Sea of Japan during the winter monsoon. Special thanks are due to Mr. Toshiro Kamiko for assisting the authors to obtain valuable ship reports from the Pacific. The authors are also greatly indebt- ed to Messrs. Yasuaki Tsuruoka for the collection of Russian ship reports and to Kazuo Watanabe and Dr. Ichiro Imai for the continuous help extended to them throughout this research.

\section{References}

Ackerman, B., 1959: The variability of the water contents of tropic cumuli. J. Meteor., 16, 191198.

Asai, T., 1964: Photographic observation of clouds by aircraft during the snowfall period in the Hokuriku District. J. meteor. Soc. Japan, 42, 186-196.

_ 1966: Cloud bands over the Japan Sea off the Hokuriku District during a cold air outburst. Papers in Meteor. and Geophys., 16, 179-194.

Chandra, K., 1938: Instability of fluids heated from below. Proc. Roy. Soc., A164, 231-241.

Fujita, Tetsuya and H. Grandoso, 1965: A proposed method of estimating cloud-top temperature, cloud-cover, and emissivity and whiteness of clouds from short- and long-wave radiation data obtained by TIROS scanning radiometers. SMRP Research Paper, 48, University of Chicago.

Fujita, Toshio and T. Honda, 1965*: Observational estimation of evaporation and sensible heat transfer from the Japan Sea in winter. Tenki, 12, 204-213.

Fukatsu, H., 1963*: On the snow shower in Tokai and Hokuriku Districts as seen by radar echoes. Ibid., 10, 373-377.

Higuchi, K., 1963: The band structure of snowfall. J. meteor. Soc. Japan, 41, 53-70.

Hubert, L. F., 1966 : Mesoscale cellular convection. MSL Report, 37, $68 \mathrm{pp}$.

Ishihara, K., Y. Toyama, K. Okada and S. Koike, $1947^{*}$ : Report of the meteorological and oceanographical observations in the middle Japan Sea between Niigata and Nashin. Hokuriku Kenkyu Kaishi, 2, 213-225.

Ito, N., 1958: On the evaporation from the Japan Sea during the winter monsoon. J. meteor. Res., 10, 173-178.

-1960 : On the energy exchange between the sea surface and the air. J. meteor. Soc. Japan, 38, 73-79.

Jacobs, W. C., 1942: On the energy exchange between sea and atmosphere. J. Marine Res., 5, $37-66$.

- 1943: Sources of atmospheric heat and moisture over the north Pacific and north Atlantic Oceans. Ann. N. Y. Acad. Sci., 44, $19-40$. 
Kawamura, T., 1961*: The synoptic climatological consideration of the winter precipitation in Hokkaido. Geograph. Rev., 34, 583-595.

- 1964*: The synoptic climatology of the winter monsoon in Japan. Ibid., 47, 64-78.

Kreuger, A. F. and S. Fritz, 1961: Cellular cloud patterns revealed by TIROS I. Tellus, 13, 1-7.

Kuettner, J., 1959: The band structure of the atmosphere. Ibid., 11, 267-294.

Manabe, S., 1957: On the modification of the air mass over the Japan Sea when an outburst of cold air predominates. J. meteor. Soc. Japan, 35, 311-326.

- 1958: On the estimation of energy exchange between the Japan Sea and the atmosphere and the sea. Ibid., 36, 123-133.

Matsumoto, S. and K. Ninomiya, 1965: An aerophotographic observation of convective clouds in the vicinity of a cold dome center. Ibid., 43, 218-230.

1966: Some aspects of cloud formation and its relation to the heat and moisture supply from the Japan Sea under a weak winter monsoon situation. Ibid., 44, 60-75.

Neiburger, M., 1949: Reflection, absorption, and transmission of insolation by stratus cloud. $J$. Meteor., 6., 98-104.

Ninomiya, K., 1964: Water substance budget over the Japan Sea and the Japanese Islands during a period of heavy snowstorm. J. meteor. Soc. Japan, 42, 317-329.

Penman, H. L., 1956: Estimating evaporation. Trans. Amer. geoph. Union, 37, 43-50.

Squires, P., 1958: The spatial variation of liquid water and droplet concentration in cumuli. Tellus, 10, 372-380.

Tatehira, R., and H. Fukatsu, 1965* : Radar analyses of Hokuriku heavy snowfall. Tenki, 12, 319322.

Warner, J., 1955: The water content of cumuliform cloud. Tellus, 7, 449-457.

* Original text in Japanese

\title{
冬の季節風下の西太平洋における雲の発生, 分布および 蒸発に関する気象衛星学的研究
}

\author{
土 屋清 \\ 気象庁予報部 \\ 藤田哲也 \\ シカゴ大学, 地球物理学教室
}

気象衛星写真と放射データにより，冬の季節風下の雲の発生し始める場所を調べた結果，海上で雲の発生し始める 場所と陸地との距離は, 風上側の地形と季節風の強さに密切に関係していることが実証された。

雲の発生後のパターンは，風の垂直シャーと支配される。すなわち，シャーが小さい $\left(<5 \times 10^{-3} \mathrm{sec}^{-1}\right)$ ときとは 対流セル状であるが，大さくなるにつれて風向に直角になり，さらに大きく $\left(>7 \times 10^{-3} \mathrm{sec}^{-1}\right)$ なると平行になる。

放射データから緯度, 経度 1 度の四辺形内の平均雲量を計算し, この雲量と高層観测資料を併用して, 空気中の水 分の量を推定することを試みた。このようにして得た水分の量は，冬季の水収支の計算飞は特に有効である。その収 支と Jacobs の蒸発の式から期待される蒸発量と比較した。結果はだいたいよく合ろようである。また季節風の強い ときの雲中の水分の量は, 断熱仮定から期待される量の 0.6 倍ぐらいである。 